Revista Complutense de Educación

ISSNe: 1988-2793

http://dx.doi.org/10.5209/RCED.59232

\title{
Políticas educativas y construcción de personalidades neoliberales y neocolonialistas
}

Autor: Jurjo Torres Santomé

Editorial: Morata

Año de publicación: 2017

Número de páginas: 270

ISBN: 978-84-7112-821-8.

En esta nueva obra del Catedrático de la Universidad da Coruña, Jurjo Torres Santomé, se hacen visibles las funciones que, en cada momento histórico, desempeña el sistema educativo y cómo, al estar al servicio de un determinado modelo de sociedad, se acompañan de un currículum idiosincrásico que dota de una estipulada selección de contenidos curriculares, según el modelo de sociedad que se pretende.

El autor expone que, si analizamos el currículum oculto de muchas de las rutinas que rigen la vida de las aulas, los contenidos de las asignaturas, las tareas escolares, los modelos de evaluación y las interacciones del alumnado entre sí y con el profesorado, se puede constatar que, al igual que en otras esferas sociales, el sistema educativo suele discriminar a los colectivos que viven en la pobreza. El contexto está contribuyendo a construir un sentido común para que determinadas realidades injustas no se perciban, y sirvan de justificación a los grupos dominantes para la selección y la imposición de los contenidos culturales que se consideran que beben ser el objeto de atención preferente por parte del sistema escolar.

En el primer Capítulo se analiza la educación como tarea compleja que va más allá de transmitir un determinado bagaje cultural y de potenciar unas determinadas capacidades, según la clase social, género, etnia, nacionalidad, edad, lugar de residencia, capacidad, etc. Razonadamente, para entender el momento presente, se precisa sacar a la luz las características de las políticas económicas, financieras, laborales, las ideologías políticas que las avalan y, en consecuencia, cómo se ofrece a la ciudadanía las políticas que pueden resolver los problemas y las injustas condiciones de vida de la mayoría de la ciudadanía.

En el segundo Capítulo se evidencia cómo el actual modelo de personalidad y subjetividad que se pretende conformar y perpetuar exige reformar el sistema educativo para primar un determinado tipo de contenidos, competencias y valores, unas determinadas áreas de conocimiento y asignaturas y, además, relegar y desvirtuar otras que podrían amenazar la viabilidad de formar un determinado modelo de personalidad. Para ello, se potencia una determinada selección cultural, se trata de condicionar la forma de estudiar y de poder analizar el verdadero valor y las auténticas potencialidades de los contenidos, procedimientos, las actitudes y los valores de lo que se aprende, al convertir las evaluaciones cuantitativas y comparativistas en el eje orientador del trabajo y de la vida de las aulas y de los centros educativos. De esta manera, se dificulta cualquier innovación que pretenda desarrollar capacidades crí- 
ticas, reflexivas, creativas, colaboradoras, solidarias y democráticas, empoderando a alumnado para convertirse en ciudadanos con criterio crítico, capaces de desafiar intelectualmente al poder dominante, ofreciendo alternativas posibles que conduzcan al éxito de todos, sin discriminaciones.

En el tercer Capítulo de reflexiona sobre los motivos que provocan que siga abierta e, incluso, avance la doble red de instituciones escolares: la pública y, por otra parte, la red privada y la privada-concertada. Se insiste sobre la necesidad de defender y apostar por la educación pública de calidad, lo que requiere conocer las funciones que puede realizar con éxito y, al tiempo, qué defectos tienen algunas instituciones públicas. Por tanto, que las instituciones escolares públicas sean un proyecto destinado a educar a una ciudadanía democrática, justa, inclusiva, sustentable y optimista, es una tarea que requiere un mayor compromiso de los partidos políticos, de los sindicatos, de las organizaciones comunitarias, del profesorado, de las familias y del propio alumnado.

En el último Capítulo se subraya la necesidad de atender a la formación y actualización del profesorado para conseguir una educación de calidad. Se apuesta por un profesorado que, como ciudadanos activos, intelectuales públicos, y profesionales críticos y responsables, sean parte irreemplazable en la conformación de una sociedad verdaderamente democrática y, por tanto, agentes muy activos contra las políticas (des)educativas oficiales que padecemos.

Un libro muy necesario, aquí y ahora, recomendado a todas las personas que apuesten por una sociedad más justa y solidaria, en la que el motor principal de su construcción sea la educación.

Ascensión Palomares Ruiz Ascension.Palomares@uclm.es Universidad de Castilla-La Mancha 